\title{
Social Anxiety in Relation to Self-Esteem among University Students in Jordan
}

\author{
Odeh Suleiman Murad ${ }^{1}$ \\ ${ }^{1}$ Al-Shoubak University College, Al-Balqa Applied University, Jordan \\ Correspondence: Odeh Suleiman Murad, Al-Shoubak University College, Al-Balqa Applied University, Jordan.
}

Received: October 28, 2019

Accepted: December 3, 2019 Online Published: January 29, 2020

doi:10.5539/ies.v13n2p96

URL: https://doi.org/10.5539/ies.v13n2p96

\begin{abstract}
People with social anxiety demonstrate different behavioral aspects such as nervousness, apprehension, fear, and concern that negatively affect their personal traits and self-esteem. The current study is designed to identify the relationship between social anxiety and self-esteem among university students. To achieve this purpose, the descriptive correlation approach was utilized. Social anxiety and self-esteem scales were applied to a sample of 334 university students in Jordan. The study results revealed a low level of social anxiety and a high level of self-esteem among participants. In addition, there was a statistically significant negative correlation between the level of social anxiety and self-esteem among participants. The study recommended holding workshops and seminars for fresh students at the beginning of each academic year, to alleviate their feeling of stress and social anxiety and to raise the level of their self-esteem.
\end{abstract}

Keywords: social anxiety, self-esteem, university students

\section{Introduction}

Social anxiety is one of the most common psychological disorders experienced in our present time. Due to its prevalence, many studies have investigated social anxiety as one of the most crucial emotional disorders causing several psychological and behavioral problems. People with social anxiety experience fear and uneasiness in social performance and interactional situations, which have a significant negative impact on the various aspects of their life (Alansari, 2004; Muammariyah, 2009).

According to (Izgic, Akyuz, Dogan, \& Kugu, 2004), there has been a recently increasing interest in social anxiety because of the higher diagnosed cases and since it leads to severe anxiety and depression. Though it is not a new phenomenon, psychologists have started to concern about social anxiety since its inclusion, for the first time, as one of the psychiatric disorders within the Diagnostic and Statistical Manual of Mental Disorders, Third Edition (DSM-III) published by the American Psychiatric Association (APA) in 1980.Since when, social anxiety has been regarded as a special case of phobia related to different social situations (Debra \& Richard, 2002).

In the nineteenth century, psychologists and educators have shown remarkable interest in studying mental disorders, especially social anxiety and in the twentieth century, social anxiety is regarded as a serious problem, while the twenty-first century is referred to as the age of anxiety (Sherbini, 2010).

Ahrens-Eipper and Hoyer (2007) and Kessler (2003) lay emphasize that some mental disorders, including Social Anxiety, appear in the age of (6-12) years old and that they badly evolve if not treated early. Based on the International Classification of Mental and Behavioral Disorders (ICD-10) issued by the World Health Organization (WHO), social anxiety is classified as generalized social phobia (Van Ameringen et al., 2001).

Schneier, Johnson, Horing, Liebowitz, and Weissman (1992) reported that the prevalence of social anxiety among females is higher than males. The study indicates that individuals with poor educational status, never been married, being unemployed and living with parents with social phobia are more vulnerable to social phobia. Furthermore, socially anxious people have negative thoughts about themselves and lower self-esteem more than their peers have. Zahran (2010) points out that people with social anxiety demonstrate different behavioral aspects such as nervousness, apprehension, fear, and concern that negatively affect their personal traits and self-esteem. According to Maslow's hierarchy of human needs, self-esteem is one of the most essential psychological needs. It represents the key motivation for self-actualization and success in the various aspects of life, such as social interactions, personal relations and creative fields (Alhagery, 2011). 
Abu Jado (2015) defines self-esteem as the general self-assessment of the individual's mental, social, emotional, moral and physical characteristics. Therefore, the level of self-esteem is one of the basic factors that help the individual constitute a positive or negative self-realization. It affects self-confidence, self-worthiness, self-competency, and expectations relevant to the various aspects of life. Roberts et al. (2000) and Muhammad (2004) reveal that there are many factors that affect self-esteem, including environmental and social factors; i.e. the family, different institutions such as schools and universities, peers, experiences of success or failure, and physical shape, i.e. self-image of his/her body, maturity rate, sexual maturity, and physical impairment.

Hence and based on the views of many researchers and psychologists, the current study is designed to investigate social anxiety as one of the factors affecting self-esteem. Socially anxious people experience psychological and emotional imbalance, isolation and fear of others, phobia of social participation and communication, so it highly affects the level of self-esteem. People without social anxiety have a high level of self-esteem so they can face failure and enter new situations without feeling fear or embarrassment. It indicates a negative correlation between social anxiety and self-esteem among individuals.

\subsection{Social Anxiety and Self-Esteem}

Many previous studies indicate that social anxiety interferes with other psychological disorders, such as frustration, fear, and low self-esteem. Zoccolillo (1992) reveals the inverse relationship between social anxiety and self-esteem. The higher social anxiety the individual demonstrates the lower self-esteem he/she has. On one hand, social anxiety leads to a serious change in the individual's self-image. On the other hand, self-esteem is the best mean to reach self-compatibility that helps face failure as well as difficult, different and new social situations. Therefore, the level of self-esteem affects the severity of social anxiety and vice versa. If the individual has a low level of self-esteem, he/she will deal negatively with social situations. More above, he/she will not be able to engage effectively in society. Undoubtedly, self-esteem plays the most important role in the achievement of individual success at the level of personal and professional life. It increases the individual's impulsiveness in dealing and interacting within the community. In case of failure, the individual refuses social communication and loses the feeling of enjoying the accompaniment of others. It thus represents an indication of various psychological problems such as social anxiety and low self-esteem.

It can be concluded that, if the individual experiences a constant case of anxiety, his/her self-image and consequently his/her self-esteem will be lower. Hope, Chavous, Jagers, and Sellers (2013) refer to the essential role of self-esteem in achieving self-compatibility, positive psychological stability, and academic achievement.

Many previous studies have dealt with social anxiety in relation to several psychological variables, such as self-esteem, aggression, social rejection, satisfaction with body shape, among others. However, no previous study investigated the relationship between social anxiety and self-esteem in Ma'an governorate of Jordan, except for Murad (2017) that dealt with social anxiety among university students in the light of some variables.

Shamma (2015) conducted a study about social anxiety in relation to self-esteem among the pupils of the first ring of basic education in Homs, Syria. Social anxiety and self-esteem scales were applied to a sample of 426 pupils. The results showed a significantly negative correlation between self-esteem and social anxiety among participants. In addition, there were no statistically significant differences in the level of social anxiety and self-esteem due to the variable of gender. It recommended training socially anxious pupils on social and emotional skills to adjust their reactions in various social interactions and engaging them in school and social activities to help constitute appositive self-image and increase self-acceptance.

Alati (2015) investigated the relationship between self-esteem and social anxiety among the first-year students of English Language. Social anxiety and self-esteem scales were applied to a sample of 100 students. The results showed a high level of self-esteem and a low level of social anxiety among participants. There was a negative correlation between social anxiety and self-esteem among participants. In addition, there were statistically significant differences in the level of social anxiety due to the variable of gender, favoring females. There were no statistically significant differences in the level of self-esteem due to the variable of gender.

Abu lkushik (2014) aimed to clarify the relationship between self-esteem and social anxiety among special education students at Al-Balqa Applied University. Social anxiety and self-esteem scales were applied to a sample of 177 students. The results revealed an average level of self-esteem and a low level of social anxiety among participants. Thus, there were a negative correlation between self-esteem and social anxiety among participants. The study recommended holding seminars for fresh students to alleviate their feelings of tension and anxiety associated with university enrollment and to raise the level of their self-esteem.

Hassan and Ali (2014) studied social anxiety in relation to self-esteem among the students of the Faculty of 
Physical Educational Muthanna University. Social anxiety and self-esteem scales were applied to a sample of 136 students deliberately selected from the Faculty of Physical Education. The results indicated a level of social anxiety and a significant level of self-esteem among participants. There was an inverse relationship between social anxiety and self-esteem among participants. The study recommended instilling confidence and willpower among students to achieve their goals, engaging students in activities and conversations, and encouraging competition among students.

Al-Ali, Singh, and Baqer (2011) aimed to identify the relationship between social anxiety and social skills, self-esteem and self-confidence among teenagers. The scales of social skills, social anxiety, self-confidence, and self-esteem were applied to 338 students selected from Kuwaiti secondary schools. The results indicated significant differences in the participants' scores in the four variables due to the gender variable. It also showed an inverse relationship between social anxiety and social skills and self-esteem among participants.

Cheung (2006) aimed to identify the factors that influence the level of social anxiety among higher education students in China. It also aimed to identify the impact of social anxiety on self-esteem. It was conducted two days before the final exams to 589 students. The results concluded that students who attend evening classes and have full-time work during the day demonstrate a higher level of social anxiety. The results also showed that social anxiety has a statistically significant effect on self-esteem among participants.

Izgic et al. (2004) aimed to identify the relationship between social phobia and self-esteem. The scales of social anxiety, self-esteem and body-self relations were applied to 1003 students. The study concluded that self-esteem was lower among participants with social phobia than among those without social phobia.

Most of the previous studies confirmed a negative correlation between social anxiety and self-esteem, concluding that there is a degree of social anxiety and self-esteem among participants. The current study applies the scales of social anxiety and self-esteem to university students specialized in applied technical disciplines. In addition, it is the first study that investigates the relationship between social anxiety and self-esteem in Ma'an governorate of Jordan.

In addition to the above, university students are the elite of any society who seek to accomplish progress and development. They are the dependents of their society as they represent the most important element and the strongest pillar of growth and development. They are constantly undergoing continuous social interaction and different psychological pressures due to contemporary crises and psychological problems resulting from cultural and cognitive openness, the multiplicity of roles and the increasing consequences. Social anxiety is perhaps the most critical psychological problems faced by young people. University students demonstrate social anxiety in performance, initiative, discussion, and dialogue with their peers and with other members of the society. As a result of confusion and embarrassment, they avoid a lot of social situations that require utilizing the skills of confrontation, communication and social integration.

\section{Research Problem}

A person with a high degree of social anxiety cannot achieve progress in various areas of life and cannot do many basic activities. This negatively affects his/her performance and value as an effective member of society where self-esteem and social efficiency become desirable qualities. The feeling of social anxiety extends to affect the student's effectiveness and ability to express, and fear of embarrassment. These feelings negatively affect this/her self-esteem. There is no doubt that social anxiety and self-underestimation lead to failure in establishing social relations with various members of the society. Consequently, social anxiety and self-esteem play the most vital role in the individual's success or failure, especially at the university stage. The current study problem is represented by exploring the relationship between social anxiety and self-esteem among university students in Jordan.

\subsection{Research Questions}

The study attempts to answer the following questions: What is the level of social anxiety among university students in the governorate of Ma'an? What is the level of self-esteem among university students in the governorate of Ma'an? Is there a statistically significant correlation at the level of $(\alpha \leq 0.05)$ between the level of social anxiety and self-esteem among university students in the governorate of Ma'an?

\subsection{Research Terminology and Procedure Definitions}

1) Social anxiety: Stein and Walker (2011) define it as intense and persistent fear of social situation or social performance when the person deals with people who he/she do not know, or being observed by others. The person fears that his/her acting is insulting or causing confusion. It is defined procedurally as the degree that the examinee obtains in the social anxiety scale. 
2) Self-esteem: The Canadian Mental Health Association (CMHA) defines self-esteem as having a healthy view of yourself, a quiet sense of self-worth, and a positive outlook. It is being able to see all your abilities and weaknesses together, accepting them, and setting realistic goals (Canadian Association Mental Health, 2013). It is defined procedurally as the degree that the examinee obtains in the self-esteem scale.

3) University students: University students enrolled in the academic year 2017/2018 in the university colleges of Al-Shoubak and Ma'an.

\subsection{Limitations and Determinants}

1) Spatial limitations: The university colleges of Al-Shoubak and Ma'an in the governorate of Ma'an, Jordan.

2) Temporal limitations: Data were collected during the second semester of the academic year 2017/2018.

\section{Methodology}

To achieve the study objectives, the descriptive correlation approach was adopted. It helps study the current situation of the phenomenon through description, data collection, and analysis depending on field study.

\subsection{Population and Sampling}

The study population was composed of all the university students in the university colleges of Al-Shoubak and Ma' an numbered 426 students in 2017/2018, according to the official records of the admission and registration sections in the two colleges. Stratified random sampling was adopted to select the study sample. It consisted of $78 \%$ of the population, i.e. 334 male and female students.

Table 1. Distribution of the study sample according to the variables of the study $(\mathrm{N}=334)$

\begin{tabular}{cccc}
\hline \multirow{2}{*}{ Study Year } & \multicolumn{2}{c}{ Gender } & \multirow{2}{*}{ Total } \\
\cline { 2 - 3 } & Male & Female & \\
\hline First & 40 & 50 & 90 \\
Second & 42 & 52 & 94 \\
Third & 33 & 42 & 75 \\
Fourth & 48 & 27 & 75 \\
Total & 163 & 171 & 334 \\
\hline
\end{tabular}

\subsection{Tools}

After reviewing the relevant educational literature and psychological scales, the following tools were utilized:

1) Social anxiety scale: The social anxiety scale developed by Murad (2017) was adopted. It consisted of (28) items divided into five domains: physical symptoms (7) items, difficulty of communication and self-express (7) items, fear of social situations (7) items, dispersion of ideas (4) items and lack of self-confidence (3) items. Each item has four alternatives to answer: Completely agree (4) degrees, mostly agree (3) degrees, slightly agree (2) degrees, and completely disagree (1) degree.

2) Self-esteem scale: The self-esteem scale developed by Melhem (2012) was adopted. It consisted of (30) items, each of which has five alternatives to answer, including: Completely agree (5) degrees, mostly agree (4) degrees, slightly agree (3) degrees, disagree (2) degrees, and completely disagree (1) degree.

\subsection{Research Procedure}

1) Identifying the study sample.

2) Verifying the tools validity and reliability:

a) The social anxiety scale: To verify the scale validity, the correlation coefficients were calculated between the score of each item of the scale and its domain and the total score of the scale. The results show that all the correlation coefficients are statistically significant. The correlation coefficients between each domain of the scale and the total scale ranged from 0.76 to 0.86 and all of which are statistically significant, indicating that all the domains contribute to the identification of the level of social anxiety. It also shows that most correlation coefficients are positive and statistically significant ranged from 0.40 to 0.67 , indicating the construct validity of the scale.

Reliability coefficient was also calculated using test-retest reliability: The scale was applied to a pilot sample consisting of 35 students and applied again to the same sample after two weeks. Pearson correlation coefficient 
was calculated and got (0.82), indicatingan acceptable reliability of the scale as explained in Table 2 .

Table 2. Pearson correlation coefficient of the domains of social anxiety scale and the total scale

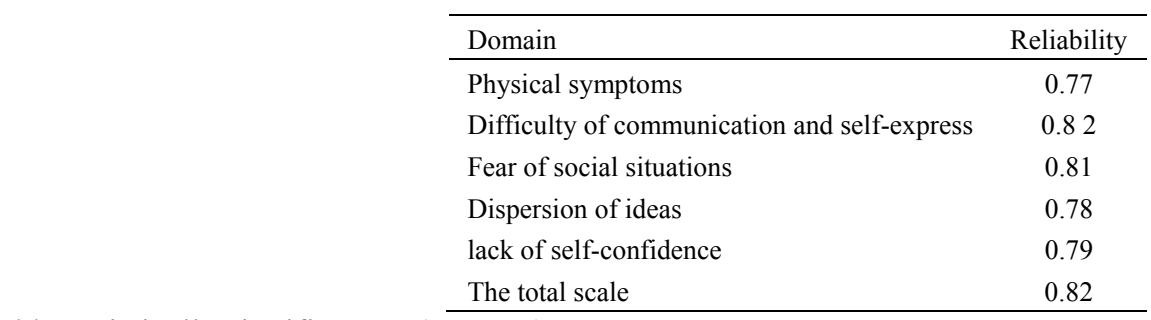

** Statistically significant at $(\alpha \leq 0.01)$.

b) Self-esteem scale: To verify the scale validity, the correlation coefficients were calculated between the score of each item of the scale and its domain and the total score of the scale. The result shows that all of them have significance value.

Reliability coefficient was calculated using test-retest reliability: The scale was applied to a pilot sample consisting of 35 students and applied again to the same sample after two weeks. Pearson correlation coefficient was calculated and got (0.81), indicating an acceptable reliability of the scale. In order to verify internal consistency reliability, Cronbach's Alpha equation utilized. It reached (0.87), indicating an acceptable reliability of the scale.

\subsection{Criterion Validity}

Social anxiety scale: To verify the level of social anxiety among participants, the regression of (1-1.99) low, (2-2.99) average, and (3-4.0) high was adopted depending on the arithmetic means of the participants' responses.

Self-esteem scale: To verify the level of self-esteem among participants, the regression of (1-2.33) low, (2.34-3.67) average, and (3.68-5.0) high was adopted depending on the arithmetic means of the participants' responses.

\section{Results and Discussion}

First Question: what is the level of social anxiety among university students in the governorate of Ma'an?

Table 3. Means, SD, level of social anxiety, and ranks of participants' responses to the domains of the social anxiety scale

\begin{tabular}{clccccc}
\hline No. & Domain & Item & Mean & SD & Social anxiety level & Rank \\
\hline 1 & Physical symptoms & 7 & 1.65 & 0.52 & Low & 5 \\
2 & Difficulty of communication and self-express & 7 & 2.02 & 0.60 & Average & 3 \\
3 & Fear of social situations & 7 & 1.92 & 0.55 & Low & 4 \\
4 & Dispersion of ideas & 4 & 2.13 & 0.62 & Average & 2 \\
5 & lack of self-confidence & 3 & 2.14 & 0.71 & Average & 1 \\
& The total scale & 28 & 1.97 & 0.48 & Low & \\
\hline
\end{tabular}

Table 3 illustrates that the arithmetic means of the scale domains ranged from 1.65 to 2.14 with a standard deviation of (0.52-0.71). 'Lack of self-confidence' rank first and got the highest arithmetic mean of (2.14) with an average level of social anxiety. However, 'physical symptoms' ranked fifth and got the lowest arithmetic mean of (1.65) with a low level of social anxiety. The level of social anxiety in the other domains of the scale ranged between low and medium. The total scale obtained an arithmetic mean of (1.97), standard deviation of (0.48), and a low level of social anxiety.

In addition, arithmetic means, standard deviations, and the level of social anxiety of the participants' responses to the items of the social anxiety scale were calculated. The results showed that the arithmetic means of students' responses to the items of the social anxiety scale ranged from 1.52 to 2.50 , and the level of social anxiety among students ranged between low and average. The arithmetic mean of the total scale was (1.97) with a standard deviation (0.48) and the level of social anxiety was low.

This result can be explained that students at this stage move from secondary school to university life. It represents a new life for the student, which affords psychological balance, freedom of expression, and unrestricted 
conversation. The student thus feels his/her importance as an active builder of the society and the homeland. Furthermore, the relatively low number of students in the university colleges of Al-Shoubak and Ma'an helps reduce the causes of social anxiety through student integration and engagement in curricular and extracurricular activities. As a result of promoting participation and social work and instilling self-confidence, students develop positive interactive behaviors.

Due to the low number of students, a family relationship has been established between the teaching and administrative staff and the students. This kind of educational environment helps alleviate psychological pressure among students. More above, student in-campus housing increase social inter dependence and feelings of reassurance and safety reflected on reducing the level of social anxiety among them.

Al-Balqa Applied University adopts knowledge economy in education, i.e. the student is the center of the teaching-learning process and a source of information. The academic disciplines taught in the colleges in question are of a technical and practical nature. Consequently, students practice many technical skills during study and participate in the implementation of many activities. These practices help alleviate the fear of facing peers and engagement in positive interaction with others.

This result is consistent with Murad (2017), Abu lkushik (2014), and Alati (2015) which reached a low degree of social anxiety among university students. However, it is inconsistent with Hassan and Ali (2014) that showed a high level of social anxiety among students and the significant differences in the level of social anxiety were in favor of females.

Second Question: What is the level of self-esteem among university students in the governorate of Ma'an?

The results showed that the arithmetic means of students' responses to the items of self-esteem scale ranged from 1.67 to 4.37 . 'I wish my body was more consistent' got the highest arithmetic mean (4.37) and a high level of self-esteem. However, 'I enjoy a great love of others' obtained the lowest arithmetic mean (1.67) and a low level of self-esteem. Most of the scale items got a high level of self-esteem, as the arithmetic mean of the total self-esteem was (3.25) with a standard deviation of (0.35) and a high degree of self-esteem among participants.

This finding can be explained that the level of self-esteem was inversely correlated with the level of social anxiety among participants. The lower social anxiety level the student has, the higher self-esteem and self-worthiness he/she feels. Undoubtedly, self-esteem has an effect on the student's psychological mood. The balanced psychological mood of the student leads to the formation of the appropriate social image and consequently social integration with peers, friends and parents. The student has thus the desire to achieve more achievements and successes, which lead to higher self-esteem, avoidance of many disorders and problems, such as social anxiety and other mental disorders.

This result is consistent with Alati (2015) and Hassan and Ali (2014) who indicated a high level of self-esteem among the study sample. It is inconsistent with Abu lkushik (2014) which showed an average level of self-esteem among university students.

Third Question: Is there a statistically significant correlation at the level of $(\alpha \leq 0.05)$ between the level of social anxiety and self-esteem among university students in the governorate of Ma'an?

Table 4. Correlation coefficients between the domains of the social anxiety scale and the total scale and the self-esteem scale

\begin{tabular}{clc}
\hline No. & Domains of social anxiety scale & Self Esteem Scale \\
\hline 1 & Physical symptoms & -0.38 \\
2 & Difficulty of communication and self-express & $-0.54^{* *}$ \\
3 & Fear of social situations & $-0.55^{* *}$ \\
4 & Dispersion of ideas & $-0.44^{*}$ \\
5 & lack of self-confidence & $-0.56^{* *}$ \\
\multicolumn{2}{c}{ Total social anxiety } & $-0.55^{* *}$ \\
\hline
\end{tabular}

* Statistically significant at $(\alpha \leq 0.05) ; * *$ Statistically significant at $(\alpha \leq 0.01)$.

Based on the results displayed in Table 4, there is a negative correlation between self-esteem and social anxiety as the correlation coefficient between them reached (0.55), statistically significant at $(\alpha \leq 0.01)$. All the domains of the social anxiety scale have an inverse correlation with self-esteem and statistically significant except for the first domain of 'physical symptoms'. The correlation coefficient reached $(0.38)$. 
This result is attributed to the level of social anxiety among students negatively affects their activities, self-expression in various situations, and assessment of these situations. In turn, it is reflected on their self-awareness, especially when compared with their peers. It also leads to depression and lower self-esteem.

It can be concluded that social anxiety is associated with self-esteem. Individuals with high levels of anxiety suffer from a negative self-assessment, and therefore have behavioral preparations for incompatibility. Individuals with low anxiety levels have higher self-esteem and behavioral preparations for compatibility.

This result is consistent with Shamma (2015), Alati (2015), Abu lkushik (2014), Al-Ali et al. (2011), and Izgic et al. (2004) which concluded a negative correlation between social anxiety and self-esteem and showed that individuals with higher levels of anxiety and shyness in social situations have higher levels of conflicting self-awareness.

\section{Recommendations}

1) Applying social anxiety tests to students at different ages to address social anxiety issues in its infancy stages.

2) Encouraging students and support them from parents, other students, and teachers to discuss various topics that help them develop self-express, and not to embarrass them when they make mistakes while expressing themselves or answering questions.

3) Holding workshops and seminars for fresh students at the beginning of each academic year, to alleviate their feeling of stress and social anxiety and to raise the level of their self-esteem.

4) Promoting the participation of students with low self-esteem in social activities, collaborative work, and social engagement to help them form a positive self-image.

\section{References}

Abu Jado, S. M. (2015). The psychology of social upbringing. Dar Al-Masirah for Publishing, Distribution and Printing, Amman: Jordan.

Abu lkushik, E. O. (2014). The Relationship between self-esteem and social anxiety among special education students at Al-Balqa Applied University (Unpublished MA thesis). Al-Balqa Applied University, Salt: Jordan.

Ahrens-Eipper, S., \& Hoyer, J. (2006). Applying the Clark-Wells model of social phobia to children: The case of a "dictation phobia". Behavioural and Cognitive Psychotherapy, 34(1), 103-106. https://doi.org/10.1017/S1352465805002523

Al-Ali, M., Singh, A., \& Baqer, F. (2011). Social anxiety in relation to social skills, self-esteem and self-confidence among adolescents. Cairo University, Journal of the Faculty of Arts, 71(Special Issue), 109-236.

Alansari, B. M. (2004). Anxiety among young people in some Arab countries: A comparative cultural study. Association of Egyptian Psychologists, Cairo, Psychological Studies, 14(3).

Alati, S. (2015). The relationship between self-esteem and social anxiety among first-year English students at Kasdi Merbah University, Ouargla. University of Ouargla, Faculty of Humanities and Social Sciences. Journal of Science Education.

Alhagery, S. (2011). Effectiveness of a collective counseling program in the development of self-esteem among the visually impaired in the Sultanate of Oman (Unpublished MA thesis). University of Nizwa, Sultanate of Oman.

Cheung, H. (2006). Factors affecting the state anxiety level of higher education students in Macau: The impact of trait anxiety and self-esteem. Assessment \& Esteem in Higher Education, 31(6), 709-725. https://doi.org/10.1080/02602930600760934

Debra, A. H., \& Richard, C. H. (2002). Phobia and social anxiety. Translated by Mohamed Naguib El-Sabwa, The Anglo-Egyptian Library, Cairo: Egypt.

Hassan, O. N., \& Ali, D. S. (2014). Social anxiety and its relation to self-esteem among students of the Faculty of Physical Education. Al-Qadisiyah Journal of Physical Education Sciences, 14(2), 91-108.

Hope, E., Chavous, T., Jagers, R., \& Sellers, R. (2013). Connecting self-esteem and achievement: Diversity in academic identification and dis-identification patterns among black college students. American Educational Research Journal, 50(5), 1122-1151. https://doi.org/10.3102/0002831213500333

Izgic, F., Akyuz, G., Dogan, O., \& Kugu, N. (2004). Social phobia among university students and its relation to 
self-esteem and body image. Canadian Journal of Psychiatry, 49(9), 630-634. https://doi.org/10.1177/070674370404900910

Kessler, R. (2003). The impairments caused by social phobia in the general population: Implications for intervention. Act Psychiatric Scandinavia, 108, 19-27. https://doi.org/10.1034/j.1600-0447.108.s417.2.x

Melhem, S. M. (2012). Effect of eating disorders, social anxiety, obsessive-compulsive disorder and self-esteem on body image satisfaction among adolescents in Jordan. Journal of the Faculty of Education, Banha University, 23(90), 1-32.

Muammariyah, B. (2009). Social anxiety: Emotional situations, prevalence ratios, gender and age differences. Journal of the Arab Psychological Network, 21-22, 135-149.

Muhammad, A. (2004).Contemporary Social Psychology. Arab Thought House, Cairo: Egypt.

Murad, O. S. (2017). Social anxiety among university students in the light of some variables. The Annual Conference (Twelfth Arab-Ninth International), Development of Higher Education qualitative output in Egypt and the Arab world in light of the Global Competitiveness, Faculty of Specific Education, Mansoura University, 12-13 April.

Roberts, A., Seidman, E., Pedersen, S., Chesir-Teran, D. L., Allen, L., Aber, J., ... Hsueh, J. (2000). Perceived family and peer transactions and self-esteem among urban early adolescents. Journal of Early Adolescence, 20(1), 25-68. https://doi.org/10.1177/0272431600020001004

Schneier, F. R., Johnson, J., Horing, C. D., Liebowitz, M. R., \& Weissman, M. M. (1992). Phobia: Co-morbidity and morbidity in an epidemiology sample. Arch Gen Psychiatry, 49(4), 282-288. https://doi.org/10.1001/archpsyc.1992.01820040034004

Shamma, Y. (2015). Social anxiety and its Relation to Self-Esteem among the first ring Students of Basic Education in the Syrian City of Homs. Al-Baath University Journal, 37(36), 139-165.

Sherbini, L. (2010). Comprehensive reference for anxiety treatment. Publications of the Arab Renaissance House, Beirut: Lebanon.

Stein, M. B., \& Walker, J. R. (2000). Triumph over shyness: Conquering shyness and social anxiety. New York: McGraw-Hill.

The Canadian Mental Health Association. (2013). Children and Self-Esteem. Bruno.

Van Ameringen, M. A., Lane, R. M., Walker, J. R., Bowen, R. C., Chokka, P. R., Goldner, E. M., ... \& Hadrava, V. (2001). Sertraline treatment of generalized social phobia: a 20 -week, double-blind, placebo-controlled study. American Journal of Psychiatry, 158(2), 275-281. https://doi.org/10.1176/appi.ajp.158.2.275

Zahran, H. (2010). Mental Health and Psychotherapy. World Books, Cairo: Egypt.

Zoccolillo, M. (1992). Co-occurrence of conduct disorder and its adult outcomes with depressive and anxiety disorders: A review. Journal of the American Academy of Child and Adolescent Psychiatry, 31(3), 547-556. https://doi.org/10.1097/00004583-199205000-00024

\section{Copyrights}

Copyright for this article is retained by the author(s), with first publication rights granted to the journal.

This is an open-access article distributed under the terms and conditions of the Creative Commons Attribution license (http://creativecommons.org/licenses/by/4.0/). 